\title{
The ArchaeoTrack Project: Use of Ground-Penetrating Radar for Preventive Conservation of Buried Archaeology Towards the Development of a Virtual Museum
}

\author{
Luca Bianchini Ciampoli \\ Dept. of Engineering \\ Roma Tre University \\ Rome, Italy \\ luca.bianchiniciampoli@uniroma3.it
}

\author{
Andrea Benedetto \\ Dept. of Engineering \\ Roma Tre University \\ Rome, Italy \\ andrea.benedetto@uniroma3.it
}

\author{
Fabio Tosti \\ School of Computing and Engineering \\ University of West London (UWL) \\ London, UK \\ Fabio.Tosti@uwl.ac.uk
}

\begin{abstract}
This paper reports the main activities planned within the context of the ArchaeoTrack research project. The project aims at creating a new ground-penetrating radar (GPR)-based methodology producing information for use of communities and local administrations within a preventive archaeology perspective. To this aim, the project provides i) identification of the most suitable GPR system for archaeological prospections, ii) development of a virtual "buried" museum and iii) data storage and visualisation in a freeware dissemination digital platform. An overview of GPR applications in archaeology is reported, followed by a description of the main structure of the project and the expected results.
\end{abstract}

Keywords- ArchaeoTrack project, preventive archaeology, ground-penetrating radar (GPR), virtual "buried" museum

\section{INTRODUCTION}

Archaeological surveys are compulsory to carry out prior to realisation of any civil engineering work. Outcomes are important to minimise the interference between soil excavations and any potential buried archaeological remains.

To date, a common practice is to develop preventive detailed surveys after a comprehensive recognition of the historical and technical information on the concerning area. Also, multiple preliminary visual inspections are carried out on site to most likely locate potential hypogeal remains. Actual surveys are then usually performed by digging inspection trenches.

In such a framework, geophysical non-destructive prospections are nowadays gaining momentum as viable solutions to major issues arising from the use of traditional trenching, i.e.,: i) uncertainty of the archaeological findings and risk of false alarms; ii) high cost of the surveys; iii) prolonged work disruptions; iv) spot information and v) need for highly-specialised professional profiles. Understanding subsurface configuration in the area of archaeology without affecting the buried materials has therefore become a prime focus of the archaeological community. Within this context, the science for analysis, measurement and quantification of archaeological structures has been designated as the area of Archaeometry [1].

Ground-penetrating radar (GPR) has proven to be a viable equipment in locating buried archaeological remains [2-5]. This is mostly due to a wide range of available antenna frequency systems (different depths of investigation) as well as to the enormous amount of information retrieved and possibility to obtain a tomographic plan view of the area investigated.

Another major methodological issue in preventive archaeology [6] is related to the effective use of information once a hypogeal archaeological remain is successfully detected.

In this regard, common practices depend on the main features of the archaeological finding. A movable object, once catalogued, is most likely removed from the site and located in dedicated conservation areas. On the contrary, a non-movable remain (i.e., an extended structure or foundation) cannot be moved from the original position. Hence, this may stand as an obstacle to the regular prosecution of the excavation works. The issue is usually sorted by modifying the original work plan in order to avoid the interference (e.g., diverting the designed track or using special technological solutions to limit the excavation depth).

In any case, unearthing hidden remains to realise archaeological attractions for visitors is extremely rare, as maintenance costs could not be sustainable. Main consequence is for the community not to benefit from significant pieces of archaeological heritage, due to only maintenance and management issues.

\section{USE OF GROUND-PENETRATING RADAR IN ARCHAEOLOGY}

GPR in archaeology has been applied for the assessment of protected sites which can never be excavated, as well as for rapid and cost-effective planning and development of mitigation projects. Within this context, rescue archaeology is a discipline that includes GPR surveys carried out at sites impacted by development. This class of applications are nowadays carried out by an increasing number of geotechnical consulting firms.

The first application of GPR in archaeology dates back to 1970s. Bevan and Kenyon [7] and Bevan [8] investigated radar reflections from buried walls and other historic structures. Similarly, Vickers and Dolphin [9] analysed radar reflections to identify potential buried walls associated with the native American Indian structures at Chaco Canyon.

A variety of GPR case studies were published in the 1980s and 1990s. Vaughn [10] used GPR to identify a sixteenth century Basque whaling station. Imai et al. [11] accurately locate pit house floors buried in volcanic soils. DeVore [12] investigated the Fort Laramie National Historic Site. 
Other relevant GPR studies from the same time period can be found in [13-16]. These studies were mainly focused on locating targets rather than providing a computergenerated image of the area with spatial development of the buried remains.

On the contrary, time-slice analysis was mostly developed over the 90s, and first research was introduced by Nishimura and Kamei [17] and Milligan and Atkin [18]. Much more sophisticated imaging was presented later using data binning and interpolation procedures [19, 20]. Relevant advances in data imaging were reached much more recently, mostly focusing on inter-line interpolation methods [21-23].

Integration of GPR with other non-destructive testing (NDT) methods has been the main research focus over the last decade. Main aim of this approach is to integrate information from equipment with different physics and investigation scales. In this regard, GPR, electrical resistivity tomography (ERT) and magnetic techniques have been mostly combined and used in various different case studies.

A first study was proposed by Negri and Leucci [24]. The authors used two-dimensional ERT imaging to detect the presence of an active fault passing under a main historical temple. GPR was instead employed to detect potential manmade structures throughout the area.

Nuzzo et al. [25] presented an integrated investigation with GPR, ERT and magnetic gradiometry to improve interpretability of results at Hierapolis, Turkey. Papadopoulos et al. [26] applied GPR and ERT techniques to archaeologically characterise a complex urban area.

More recently, Zeid et al. [27] proposed a nonconventional geophysical approach for archaeological investigations. The authors employed the Horizontal-ToVertical Spectral Ratio method (HVSR) to appreciate contrasts of acoustic impedance of inspected paleo-surfaces. In addition, the Induced Polarization tomography (IPT) was used to monitor trend of chargeability values to relate with a paleo-riverbed.

Laser scanner has also been widely applied in combination with GPR to collect very detailed geometric information of archaeological remains [28] and historical infrastructures, e.g. ancient bridges [29].

\section{The Archaeo Track Project: Aim AND OBJeCtiveS}

A solution to address the aforementioned issues has been proposed within the framework of the ARCHAEO TRACK research project (Fig. 1), coordinated by the Department of Engineering of Roma Tre University, Rome, Italy.

The project was awarded by the Lazio Region and will last for 2 years, starting from July 2018. Hence, an archaeological-worthy area - including the municipality of Rome - will be covered by the project. The main aim of the project is to develop a new GPR-based methodology producing information for use of communities and local administrations.

The method will integrate detection, preservation and valorisation of the hypogeal cultural heritage, as well as the creation of a diffused virtual museum. This would allow stakeholders to benefit from archaeological remains that, otherwise, would stay hidden and unknown to the community.

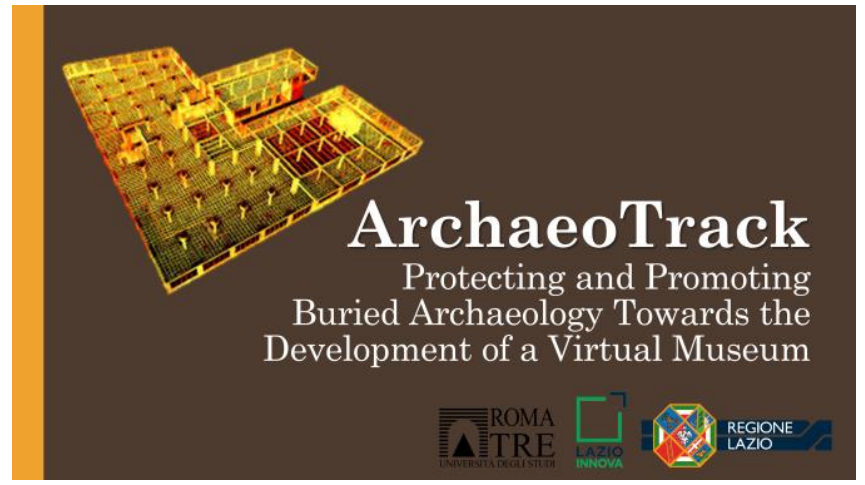

Fig. 1. The Archaeo Track project flyer.

In more detail, the project aims at achieving the following objectives:

- identification of the most suitable GPR system for archaeological prospections in terms of antenna configuration, central frequency, polarisation, etc.;

- development of dedicated survey protocols for standalone use of GPR and integrated use with other nondestructive/minor-destructive testing methods (ERT [30], synthetic aperture radar (SAR) [31], sensing probes [32] etc.);

- virtual reconstruction of the surveyed buried structures in a $3 \mathrm{D}$ environment. This will be pursued by merging together the information gathered from the interpretation of the GPR tomographic plan views (data outputs) and archaeological assessments of the area made by experienced archaeologists;

- data storage and visualisation in a freeware dissemination digital platform, to make available to communities.

\section{Methodology}

To achieve the mentioned objectives, the project is developed on the following main packages:

1) Electromagnetic testing: this package will mainly focus on gathering required knowledge on the most suitable GPR configurations for archaeological inspection purposes. A comprehensive literature review and laboratory testing will be carried out on purpose. Parameters to take into account for the development of this package are, above all, the depth of burial, the construction materials of the target object and the surrounding soil.

2) Numerical developments and modelling: the package will develop specific coding for: i) detection and identification of targets from the data collected; ii) rendering of three-dimensional features and iii) reconstruction of the structure. Various different expertise, from data processing to archaeology, are required at this stage.

3) Data collection: models produced will be tested at the real scale by performing gridded GPR surveys on different relevant sites (i.e., areas with buried archaeological remains).

4) Dissemination: a prototypal free digital platform will be developed as a virtual "buried" museum. 
This will contribute to value hidden cultural heritage and encourage dissemination of related cultural and historical information.

Fig. 2 depicts the time scheduling of the activities carried out within the various working packages.

\section{EXPECTED RESULTS}

Expected results can be listed under three main profiles, i.e., technological, methodological and applicative.

\section{A. Technological Profile}

Development of a GPR system for archaeological inspections is expected. To allow penetration and resolution fit for archaeological purposes, realisation of an antenna array system with orthogonal polarisation and central frequencies of $100-200 \mathrm{MHz}$ and $500-600 \mathrm{MHz}$ is envisaged. The system will be integrated and synchronised with GPS stations to allow data visualisation on a small scale (1:10000 $\div 1: 500$ : localisation of remains) and a large scale $(1: 1000 \div$ 1:200: identification of a more detailed layout of buried targets).

\section{B. Methodological Profile}

A major expected result is to develop a new methodology for improving the current concept of "conservation of cultural heritage".

To this purpose, it is envisaged to create a specialist software for a $3 \mathrm{D}$ rendering of buried targets. Integration of information in a 3D extended environment will possibly aid the reconstruction of complex and more extensive scenarios (e.g., interpolation of geometric, morphologic and topographic features over extended areas).

The innovation of the project is also underpinned by the multi-method approach. Merging information from various different technologies, with different working principles and scales of investigation, will contribute to increasing target detectability and accuracy of results [33].

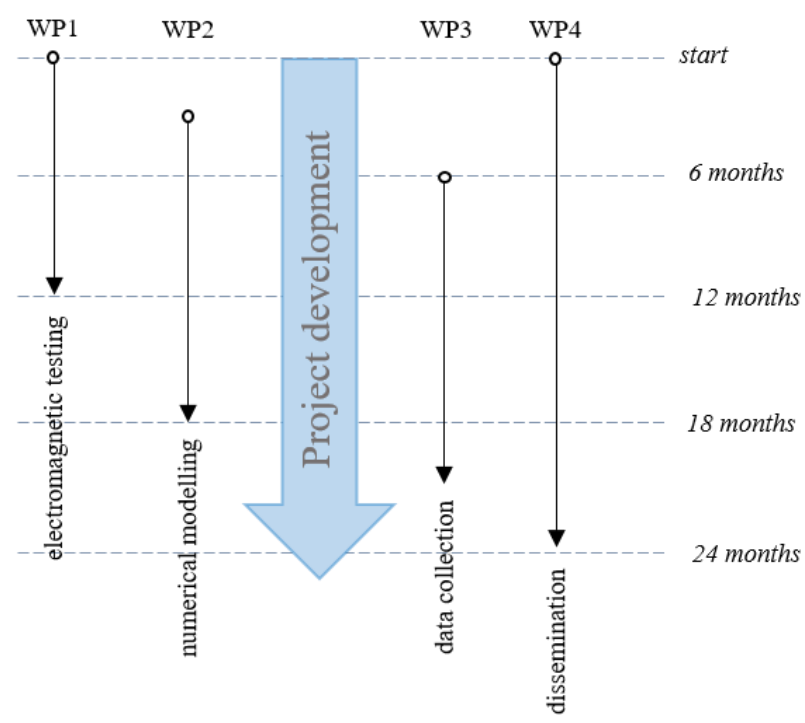

Fig. 2. Time scheduling of the planned project activities.
Within this context, use of SAR technology for collection of images from orbiting sensors was already proven to be suitable in several archaeological applications [34].

In this regard, changes in soil properties, surface roughness and moisture content are among the most relevant parameters that can be observed and related to ancient anthropic activities.

A scheme of the adopted methodological approach resulting from the development of ArchaeoTrack project is reported in Fig. 3.

The foreseen method, based on the integration of NDT surveys over a civil engineering works site, involves the detection and detailing of hidden structures, and ends with the reconstruction of the main three-dimensional features of the buried heritage.

The last step will be represented by the digital valorisation of the structure via a dedicated dissemination digital platform.

\section{Applicative Profile}

A method based on the use of NDT equipment integrated with a dedicated software will allow to tackle potential drawbacks of traditional investigation methods.

It is estimated that cost of on-site surveys will be lowered by $\sim 90 \%$. Linear (paved and unpaved roads) and areal surveys can be carried out with a productivity of $5 \div 15$ $\mathrm{km} /$ day (unpaved roads), $150 \mathrm{~km} /$ day (paved roads) and $5000 \div 10000 \mathrm{~m}^{2} /$ day (areal sites).

It is envisaged to train field operators with $12 \div 24$ hours training sessions. Higher expertise are instead required for data processing and interpretation of results.

\section{CONCLUSIONS}

This paper reports the main activities planned within the context of the ArchaeoTrack research project, coordinated by the Department of Engineering of Roma Tre University, Rome, Italy.

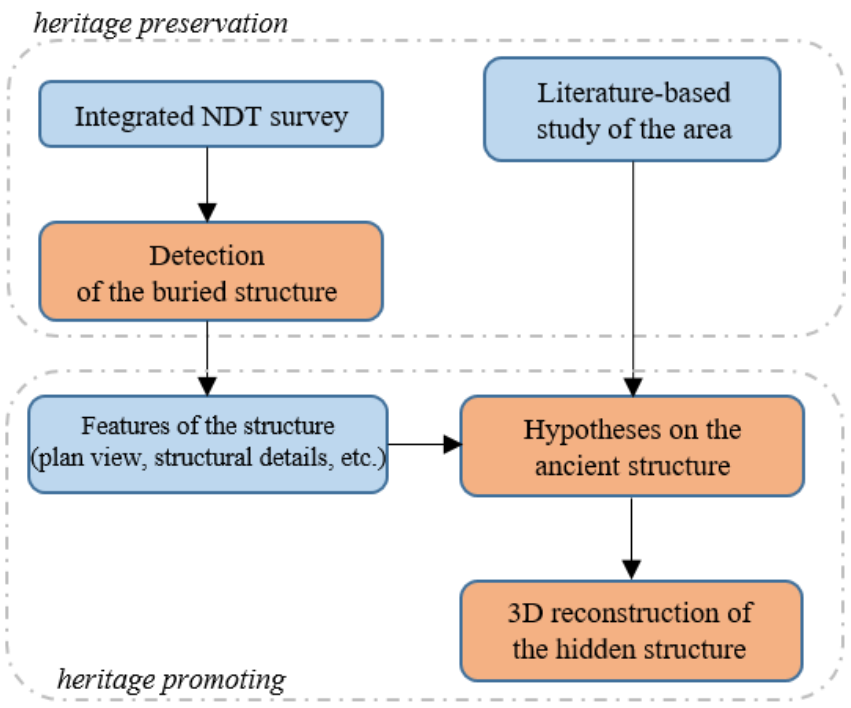

Fig. 3. Workflow of the process addressed by the project. 
The project was awarded by the Lazio Region and will last for 2 years, starting from July 2018.

It falls within the framework of the archaeological surveys prior to realisation of civil engineering works. A significant scientific contribution is herein required to minimise the interference between soil excavations and any potential buried archaeological remains.

In fact, this represents a challenging task, especially in those countries with a significant presence of buried cultural heritage.

Accordingly, the main aim of the project is to develop a new ground-penetrating radar (GPR)-based methodology capable to collect information to be transferred to local administrations.

To this purpose, the project provides i) identification of the most suitable GPR system for archaeological prospections, ii) development of a virtual "buried" museum and iii) data storage and visualisation in a freeware dissemination digital platform

To this effect, the project merges the concept of protection of cultural heritage and its digital valorisation. Specifically, the virtual visualisation of hidden structures would allow the community to benefit from cultural heritage without involving any additional cost. These are usually related to management and maintenance of archaeological remains, once these are excavated.

The project constitutes of four main packages and is expected to provide contribution to new disciplinary advances under technological, methodological and applicative profiles.

\section{ACKNOWLEDGMENT}

This work was supported by Regione Lazio, under the Framework "L.R. 13/08, Research Group Project n. 20 prot. 85-2017-14857".

\section{REFERENCES}

[1] D. Goodman et al., GPR Archaeometry, Chapt. 15 in Ground penetrating radar theory and applications, H. M. Jol Ed, pp. 479-508, 2009.

[2] L. B. Conyers, "Innovative ground-penetrating radar methods for archaeological mapping," Wiley Inter Science, vol. 13, pp. 137-139, 2004

[3] G. Leucci, G. Di Giacomo, I. Ditaranto, I. Miccoli, and G. Scardozzi, "Integrated Ground - penetrating Radar and Archaeological Surveys in the Ancient City of Hierapolis of Phrygia (Turkey)," Archaeological Prospection, vol. 20 (4), pp. 285-301, 2013.

[4] A. Benedetto, and L. Pajewski, "Civil Engineering Applications of Ground Penetrating Radar", Springer Transactions in Civil and Environmental Engineering, 2015.

[5] A. Benedetto, F. Tosti, L. Bianchini Ciampoli, and F. D'Amico, "GPR applications across engineering and geosicences in Italy: a review," IEEE Journal of Selected Topics in Applied Earth Observations and Remote Sensing, vol. 9, no. 7, pp. 2952-2965, 2016

[6] M. Corfield, "Preventive conservation for archaeological sites," Studies in Conservation, vol. 41, pp. 32-37, December 2013

[7] B. Bevan, and Kenyon, J. "Ground-penetrating radar for historical archaeology. MASCA Newsletter," vol. 11, no. 2, pp. 2-7, 1975

[8] B. W. Bevan, Ground-penetrating radar at Valley Forge, Geophysical Survey System, North Salem, New Hampshire, 1977.

[9] R. Vickers, and L. T. Dolphin, A communication about an archaeological radar experiment at Chaco Canyon: Museum Applied
Science Center for Archaeology, Univ. of Pennsylvania, Philadelphia, Newsletter, Vol. 11., 1975.

[10] C. J. Vaughn, "Ground-penetrating radar surveys used in archaeological investigations," Geophysics, vol. 51, pp. 595-604, 1986.

[11] T., Imai, T. Sakayama, and T. Kanemori, "Use of ground-probing radar and resistivity surveys for archaeological investigations. Geophysics," vol. 52, pp. 127-150, 1987.

[12] S. L. DeVore, "Ground-penetrating radar as a survey tool in archaeological investigations: An example from Fort Laramie national historic site," The Wyom. Archaeol., vol. 33, pp. 23-28, 1987.

[13] R. A. Batey, "Subsurface interface radar at Sepphoris, Israel, 1985. J. Field Archaeol., vol. 14, pp. 1-8, 1987.

[14] B. W. Bevan, The search for graves. Geophys., vol. 56, pp. 13101319, 1991 .

[15] P. M. Fischer, S.G. Follin and Ulriksen, P., "Subsurface interface radar survey at Hala Sultan Tekke," Cyprus, in Fischer, P.M. (ed.), Application of Technical Devices in Archaeology: Studies in Mediterranean Archaeology, vol. 63, pp. 48-51, 1980.

[16] P. D. Sheets, W. M. Loker, H.A.W. Spetzler, and R.W., Ware, "Geophysical exploration for ancient Maya housing at Ceren, El Salvador," National Geographic Research Report, vol. 20, pp. 645656, 1985.

[17] Y. Nishimura, and Kamei, H. "A study in the application of geophysical survey," in Pernifka, E. and Wagner, G., eds., Proceedings, Archaeometry '90 Conference, Heidelberg, April, pp. 757-765, 1990

[18] R. Milligan, and Atkin, M., "The use of ground-probing radar within a digital environment on archaeological sites," in Andresen, J., Madsen, T. and Scollar, I., eds., Computing the Past: Computer Application and Quantitative methods in Archaeology: Aarhus, Denmark, Aarhus University Press, pp. 285-291, 1993.

[19] D. Goodman, and Nishimura, Y., "Ground radar view of Japanese burial mounds," Antiquity, vol. 67, pp. 349-354, 1993.

[20] D. Goodman, Y. Nishimura, and J. D. Roger, "GPR time slices in archaeological prospection," Archaeol. Prosp., vol. 2, pp. 85-89, 1995.

[21] K. L. Kvamme, "Current practices in archaeogeophysics: Magnetics, resistivity, conductivity, and ground-penetrating radar," in Goldberg, P., Holliday, V.T. and Ferring, C. R., eds., Earth Sciences and Archaeology: New York, Kluwer/Plenum Publishers, pp. 353-382, 2001

[22] L. B. Conyers, and S. Connell, "The applicability of using groundpenetrating radar to discover and map buried archaeological sites in Hawaii," Hawaiian Archaeology Journal, Vol. 11, pp. 62-77, 2007.

[23] S. Piro, and D. Goodman, "Integrated GPR data processing for archaeological surveys in urban areas: the case of Forum (Roma)," in 12th International Conference on Ground Penetrating Radar, Birmingham, England, 2008.

[24] S. Negri, and G. Leucci, "Geophysical investigation of the Temple of Apollo (Hierapolis, Turkey)," J. Archaeol. Sci., vol. 33 (11), pp. 1505-1513, 2006

[25] L. Nuzzo, G. Leucci, and S. Negri, "GPR, ERT and magnetic investigations inside the martyrium of St Philip, Hierapolis," Turkey Archaeol. Prospect., vol. 16 (3), pp. 177-192, 2009.

[26] N. Papadopoulos, A. Sarris, M.-J. Yi, and J.-H. Kim, "Urban archaeological investigations using surface 3D Ground Penetrating Radar and Electrical Resistivity Tomography methods," Explor. Geophys., vol. 40 (1), pp. 56-68, 2009.

[27] N.A. Zeid, E. Corradini, S. Bignardi, N. Morandi, V. Nizzo, and G. Santarato, "Unusual geophysical techniques in archaeology - HVSR and induced polarization, A case history," 22nd European Meeting of Environmental and Engineering Geophysics, Near Surface Geoscience 2016

[28] S. Santos-Assunçao, K. Dimitriadis, Y. Konstantakis, V. PerezGracia, E. Anagnostopoulou and R. Gonzalez-Drigo, "Groundpenetrating radar evaluation of the ancient Mycenaean monument Tholos Acharnon tomb," Near Surf .Geophys., vol. 14 (2), pp. $197-$ 205.

[29] A. Alani, F. Tosti, K. Banks, L. Bianchini Ciampoli, and A. Benedetto, "Non-destructive assessment of a historic masonry arch bridge using ground penetrating radar and 3D laser scanner," In: 
MetroArchaeo 2017 International Conference, 23-25 Oct. 2017, Lecce, Italy.

[30] S. Negri, G. Leucci, and F. Mazzone, "High resolution 3D ERT to help GPR data interpretation for researching archaeological items in a geologically complex subsurface,” J. App. Geophys., vol. 65 (3-4), pp. 111-120, 2008.

[31] G. Franceschetti, and R. Lanari, Synthetic Aperture Radar Processing, CRC Press, London, 1999.

[32] D. W. Owsley, "Techniques for locating burials, with emphasis on the probe,” J. Forensic Sci., vol. 40 (5), pp. 735-740, 1995.
[33] R. C. Luo, C.-C. Yih, and K. L. Su, "Multisensor fusion and integration: approaches, applications, and future research directions", IEEE Sens. J., vol. 2(2), pp. 107-119, 2002.

[34] F. Chen, R. Lasaponara, and N. Masini, "An overview of satellite synthetic aperture radar remote sensing in archaeology: from site detection to monitoring," Journal of Cultural Heritage, vol. 23, pp. 5$11,2017$. 